\title{
In utero cigarette smoke exposure impairs somatic and lung growth in BALB/c mice
}

\author{
A.N. Larcombe*, R.E. Foong*, L.J. Berry*, G.R. Zosky* and P.D. Sly*,\#
}

\section{ABSTRACT: The aim of this study was to assess whether in utero tobacco smoke exposure alone affects early-life lung growth and development.}

Pregnant BALB/c mice were exposed to cigarette smoke from six cigarettes per day, or air, from day $\mathbf{8}$ to $\mathbf{2 0}$ of gestation. At $\mathbf{2}$ weeks of age, pups were weighed and had their lung volumes and lung mechanics measured.

Pups born from mothers exposed to cigarette smoke (CS pups; $n=17$ ) were significantly lighter $(6.76 \pm 0.76$ versus $7.72 \pm 0.68 \mathrm{~g})$ and had lower lung volumes $(0.123 \pm 0.02$ versus $0.149 \pm 0.02 \mathrm{~mL})$ than control pups $(n=20)$. Respiratory mechanics were adversely impacted by cigarette smoke exposure. CS pups had higher baseline airway resistance, tissue damping and tissue elastance. These differences were largely due to lower lung volumes. Both tissue damping and elastance were increased excessively in CS pups at high transrespiratory pressures, while other parameters were not affected. There were no histological differences between groups.

In utero tobacco smoke exposure significantly affects growth and development in BALB/c mice. These impacts may partially explain the susceptibility of infants born to smoking mothers to early respiratory disease and chronic respiratory disease as adults.

KEYWORDS: Cigarette smoke, in utero, lung function, mouse

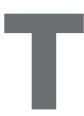
here are a plethora of epidemiological studies that link in utero and/or early-life tobacco smoke exposure to altered lung function, wheeze, bronchitis and increased prevalence and severity of asthma in children [1-10]. Children born to smoking mothers show deficits in measured indicators of lung function, such as forced expiratory volume in $1 \mathrm{~s}$, airflow at functional residual capacity and mean mid-expiratory flow [3, 11]. There is considerable difficulty, however, in separating the effects of pre- and postnatal cigarette smoke exposure on lung function, as mothers who smoke during pregnancy rarely give up after the baby is born [12] Furthermore, in human studies, it is very difficult to separate the effects of cigarette smoke exposure from the effects of other factors that may alter lung function, such as respiratory viral, aeroallergen or pollutant exposure. Thus, it is not easy to evaluate the true impact of in utero cigarette smoke exposure on developing lungs in humans [13], making the use of animal models of cigarette smoke exposure particularly relevant. Unfortunately, there is a paucity of data exploring the effects of in utero mainstream cigarette smoke exposure on early-life lung function using animal models. A number of mouse studies have considered the effects of cigarette smoke exposure on allergic airways disease [14, 15]; however, these have generally investigated adult mice and/or used inappropriate measures of lung function such as "enhanced pause" $[9,14,15]$. Previous studies in rats have shown that in utero and postnatal exposure to sidestream cigarette smoke results in lungs which are less compliant and more reactive to methacholine as measured in vitro [16]. Postnatal or in utero exposure alone did not change lung function or airway reactivity to methacholine [17]. These studies did not measure early-life lung function or lung volume, but were restricted to investigating the effects of in utero cigarette smoke exposure on the lungs of adult offspring in vitro.

The present study was designed to test the hypothesis that in utero cigarette exposure alone (i.e. without postnatal cigarette smoke exposure, exposure to allergen or other confounders) results in impaired lung function in 2-week-old mice.

\section{MATERIALS AND METHODS}

\section{Animals}

BALB/c dams (Animal Resource Centre, Murdoch, Australia) purchased at embryonic day (E)5 were

\section{AFFILIATIONS}

*Division of Clinical Sciences, Telethon Institute for Child Health Research and Centre for Child Health Research, University of Western Australia, Perth, and

\#Queensland Children's Medical Research Institute, University of Queensland, Brisbane, Australia.

CORRESPONDENCE

A.N. Larcombe

Division of Clinical Sciences Telethon Institute for Child Health Research

P.0. Box 855

West Perth

WA 6872

Australia

E-mail: alexanderl@ichr.uwa.edu.au

Received:

Oct 062010

Accepted after revision:

Jan 132011

First published online:

Feb 102011 
housed at the Telethon Institute for Child Health Research (University of Western Australia, Perth, Australia) with a 12-h/ 12-h light/dark cycle and provided with food and water ad libitum. All experiments were conducted with the approval of the Institutional Animal Ethics Committee and conformed to the guidelines of the National Health and Medical Research Council of Australia.

\section{Cigarette smoke exposure}

Dams were placed in a custom-made exposure chamber (total volume $9.2 \mathrm{~L}$ ) attached to a commercially available cigarette smoking machine (inExpose; SCIREQ ${ }_{\circledR}$, Montreal, QC, Canada). Four dams were whole-body exposed to mainstream cigarette smoke generated from three Winfield Red cigarettes $(\leqslant 16 \mathrm{mg}$ of tar, $\leqslant 1.2 \mathrm{mg}$ of nicotine and $\leqslant 15 \mathrm{mg}$ of CO; Philip Morris, Melbourne, Australia) twice per day from E8 to E20 of gestation. Cigarettes were puffed using the International Organization for Standardization standard $35 \mathrm{~mL}$ puff, once per minute such that each cigarette lasted $\sim 8 \mathrm{~min}$. 5 min were left between cigarettes for air to flush through the chamber. Throughout exposure, medical air flowed through the system at $3 \mathrm{~L} \cdot \mathrm{min}^{-1}$, to ensure oxygen levels remained adequate. Four control dams received only medical air. Dams tolerated the exposure regime well and none died during experiments. Cigarette smoke-exposed (CS) dams produced a total of 17 pups, while control (Air) dams produced a total of 20 pups.

\section{Urine cotinine}

Urine cotinine levels in dams were measured after the last exposure on day 2, 4, 6, 8, 10, 12 and 13 (24 h after the last exposure) by ELISA (Calbiotech, Spring Valley, CA, USA). Urine from a minimum of six mice was tested per day.

\section{Animal preparation}

At 2 weeks of age, pups were anaesthetised with an intraperitoneal injection of a solution containing $20 \mathrm{mg} \cdot \mathrm{mL}^{-1}$ of ketamine (Troy Laboratories, Glendenning, Australia) and $1 \mathrm{mg} \cdot \mathrm{mL}^{-1}$ of xylazine (Troy Laboratories) at a dose of $0.1 \mathrm{~mL}$ per $10 \mathrm{~g}$ body weight. Two-thirds of the dose was given initially to induce a surgical level of anaesthesia. Once anaesthetised, pups were tracheostomised with a 10-mm length of 21-gauge needle that was securely fixed in situ with surgical silk. The mouse was placed inside a whole-body plethysmograph and connected to a small animal ventilator (Minivent; Harvard, March-Hugstetten, Germany). The remaining anaesthetic was given, and the mouse was ventilated at 400 breaths $\cdot \mathrm{min}^{-1}$ with a tidal volume of $8 \mathrm{~mL} \cdot \mathrm{kg}^{-1}$ and $2 \mathrm{cmH}_{2} \mathrm{O}$ of positive end-expiratory pressure. This was sufficient to suppress spontaneous breathing efforts during measurements without the need for paralysis. Except when measurements were being made, the plethysmographic box was open to the atmosphere, and the mouse was ventilated with atmospheric air.

\section{Thoracic gas volume}

Thoracic gas volume (TGV) was measured plethysmographically as described previously [18]. Briefly, during a pause in ventilation, the box and airway opening were occluded, making the system completely airtight, and box and tracheal pressures (Pbox and $P$ trachea) were measured using pressure transducers (Validyne MP45; Validyne Engineering, Northridge, CA, USA; and model 8507C-2; Endevco, San Juan Capistrano, CA, USA, respectively) for a period of $6 \mathrm{~s}$, during which time inspiratory breathing efforts were created by stimulating the intercostal muscles with electrical impulses $\sim 20 \mathrm{~V}$ in amplitude and 1-2 ms in duration (model S44; Grass Instruments, Quincy, MA, USA). During the $6 \mathrm{~s}$ of measurement, box thermal drift was negligible (online supplementary fig. 1). Six stimulations were made per mouse. Each stimulation was analysed separately and an average taken for each mouse, such that we report one TGV measurement per animal. TGV was calculated by applying Boyle's law to the relationship between Pbox and $P$ trachea. Recordings were corrected for the thermal characteristics of the plethysmograph as previously described [18]. Briefly, Pbox was corrected for deviations from the isothermal compression of the box gas by taking into account the isothermal elastic modulus of the box, atmospheric pressure and the volume of gas in the plethysmograph. With this correction, Boyle's law can be assumed during respiratory efforts, whereby the change in box volume is equal but opposite in sign to that in thoracic volume [18]. The frequency response/ thermal characteristics of the plethysmograph were measured regularly during the experimental period and did not change over the course of experimentation. During all TGV measurements, the plethysmography box was completely sealed. Daily confirmation that the box was airtight was achieved by applying a negative pressure to the system (online supplementary fig. 1).

\section{Lung mechanics}

We measured respiratory system impedance ( $\mathrm{Zrs}$ ) using a modification of the forced oscillation technique, as previously described by our group [19]. Briefly, Zrs was measured using a wave-tube system [20] adapted for use in small animals [19, 21]. During brief periods of apnoea, oscillatory signals between 4 and $38 \mathrm{~Hz}$ (signal period $0.5 \mathrm{~s}$ ) were generated by a loudspeaker and delivered via a 2-m-long wave-tube (internal diameter $0.116 \mathrm{~cm}$ ) to tracheostomised pups. Two transducers (model 8507C-2; Endevco) were used to measure lateral pressure at either end of the wave-tube and Zrs was estimated as the load

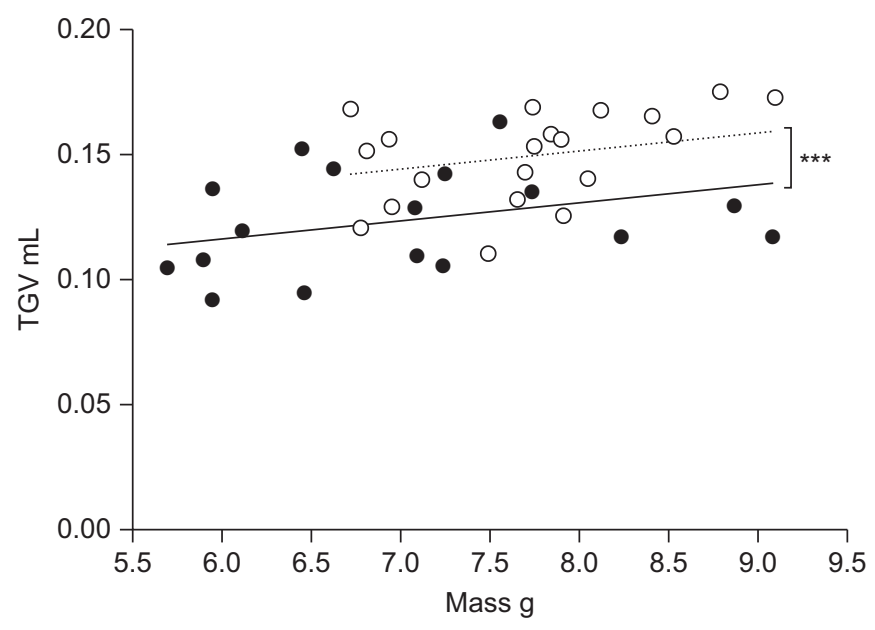

FIGURE 1. The relationship between body mass and thoracic gas volume (TGV) for 2-week-old mice born from mothers exposed to mainstream cigarette smoke during pregnancy ( $\bullet$ and $-; n=17)$ and controls $(\bigcirc$ and $\cdots \cdots ; n=20)$. Each circle represents an individual pup. Pups born from mothers exposed to mainstream cigarette smoke during pregnancy have significantly lower TGV for a given mass compared with control pups. ${ }^{* *}$ : $p<0.001$. 
impedance on the wave-tube. The constant phase model [22] was used to partition Zrs into: the airway compartment of airway resistance (Raw) and airway inertance (law); and the tissue compartment of tissue damping $(\mathrm{G})$ and tissue elastance $(\mathrm{H})$. Iaw values were negligible after correction for the inertance of the cannula and are not reported. Six measurements of baseline $Z$ rs were measured per mouse and averaged to achieve one value per animal. Zrs was measured at baseline and also continuously during slow inflation (20-s period) from a transrespiratory pressure $(P \mathrm{rs})$ of $0-20 \mathrm{cmH}_{2} \mathrm{O}$. Lung inflation was achieved by evacuating the sealed plethysmograph with a regulated vacuum source. Hysteresivity $(\eta)$ was calculated as $\mathrm{G} / \mathrm{H}[22]$.

\section{Histology}

Lungs were fixed by intratracheal instillation of $2.5 \%$ glutaraldehyde at $10 \mathrm{cmH}_{2} \mathrm{O}$ [23]. The trachea was ligated with suture and the lungs removed en bloc and stored in $2.5 \%$ glutaraldehyde. Lungs were randomly oriented to ensure that sections were isotropic and uniformly random [24], and embedded in paraffin. Sections $5 \mu \mathrm{m}$ thick were taken at $500-\mu \mathrm{m}$ intervals from a random starting point, stained with haemotoxylin-eosin and examined under light microscopy. Point counts were used to calculate parenchymal volume $(V \mathrm{p})$ and the volume of the alveolar septa $(V \mathrm{~s})$. Surface area of the alveoli $(\mathrm{Sa})$ was measured using a line intersection test grid [23].

\section{Statistics}

Analysis of mass was conducted using two-way ANOVA with sex and treatment as factors. Analysis of TGV was conducted using ANCOVA with mass as a covariate. Baseline lung function and the volume dependence of lung mechanics were compared using ANCOVA with TGV as a covariate. Data were transformed using log or power transformations when required. Histology data were analysed by unpaired t-test. Statistical analyses were performed using SigmaStat (v3.50; SPSS Science, Chicago, IL, USA) and Stata (v10; Statacorp LP, College Station, TX, USA). Unless otherwise stated, data are shown as mean \pm SD.

\section{RESULTS}

\section{Urine cotinine}

Urine cotinine was relatively stable throughout pregnancy. There was no change in urine cotinine (average 5,799 \pm $\left.2,103 \mathrm{ng} \cdot \mathrm{mL}^{-1}\right)$ between days 2 and $12(\mathrm{p}=0.55)$; however, urine cotinine decreased $24 \mathrm{~h}$ after the last cigarette exposure $\left(982 \pm 409 \mathrm{ng} \cdot \mathrm{mL}^{-1}\right)$. Cotinine was not detectable in the urine of control dams.

\section{Effect of sex}

There was no significant interaction between treatment (i.e. in utero cigarette smoke exposure or air) and sex for any parameter investigated (all $\mathrm{p}>0.24$ ). As such, unless otherwise stated, all analyses were performed on combined male and female data.

\section{Mass}

Pups born to dams exposed to cigarette smoke during pregnancy (CS pups; $\mathrm{n}=17)$ had lower masses $(6.76 \pm 0.76 \mathrm{~g})$ than control pups (Air pups; $\mathrm{n}=20 ; 7.72 \pm 0.68 \mathrm{~g} ; \mathrm{p}<0.001$ ). Litter sizes were not significantly different between treatments (t-test $\mathrm{p}=0.27$; $3.75 \pm 1.89$ for CS pups and $5.00 \pm 0.82$ for Air pups).

\section{TGV}

TGV was measured on 20 Air and 17 CS pups. CS pups had lower TGV than Air pups $(0.123 \pm 0.02 \mathrm{~mL}$ versus $0.149 \pm 0.02 \mathrm{~mL}$; $\mathrm{p}<0.001$ ); however, when mass was taken into account, there was no difference in TGV ( $\mathrm{p}=0.33$; fig. 1$)$.

\section{Baseline lung mechanics}

Baseline lung mechanics were measured on 20 Air and 17 CS pups. There were significant effects of in utero cigarette smoke exposure on baseline lung mechanics; however, for all parameters this difference was due to the smaller TGV of CS pups compared with Air pups (fig. 2). The baseline Raw of CS pups was significantly higher than that of Air pups $\left(854.3 \pm 121.3\right.$ versus $\left.761.4 \pm 93.0 \mathrm{hPa} \cdot \mathrm{s} \cdot \mathrm{L}^{-1} ; \mathrm{p}=0.01\right)$, but not after correcting for TGV $(\mathrm{p}=0.11)$. Similarly, $\mathrm{G}$ was significantly higher in CS pups compared with Air pups $(24,910$ $\pm 3,461$ versus $21,991 \pm 2,413 \mathrm{hPa} \cdot \mathrm{L}^{-1} ; \mathrm{p}<0.01$ ), but not after correcting for TGV $(\mathrm{p}=0.26)$; and baseline $\mathrm{H}$ of CS pups was significantly greater than that of Air pups $(90,320 \pm 15,885$ versus $\left.78,918 \pm 9,596 \mathrm{hPa} \cdot \mathrm{L}^{-1} ; \mathrm{p}=0.01\right)$, but not after correcting for TGV $(p=0.41)$. $\eta$ was not influenced by TGV $(p=0.84)$ and was not significantly different between CS pups and Air pups $(0.328 \pm 0.01$ versus $0.293 \pm 0.01)$.

\section{Volume dependence of lung mechanics}

The volume dependence of lung mechanics was measured in 20 Air and 17 CS pups. The volume dependencies of Raw, G, H and $\eta$ were analysed at $P$ rs $20 \mathrm{cmH}_{2} \mathrm{O}$ and at the Prs at which TGV was equal to $50 \%$ of maximum TGV (TGV50; fig. 3). All statistical analyses were conducted with TGV as a covariate. The Raw of CS pups was not significantly different from that of control pups at either TGV50 $\left(636.70 \pm 164.4\right.$ versus $557.80 \pm 95.31 \mathrm{hPa} \cdot \mathrm{s} \cdot \mathrm{L}^{-1}$; $\mathrm{p}=0.078$; fig. 4) or at Prs $20 \mathrm{cmH}_{2} \mathrm{O}(157.39 \pm 83.32$ versus 179.75 $\left.\pm 70.97 \mathrm{hPa} \cdot \mathrm{s} \cdot \mathrm{L}^{-1} ; \mathrm{p}=0.822\right)$.

Conversely, in utero cigarette smoke exposure had significant effects on both $\mathrm{G}$ and $\mathrm{H}$, even when differences in TGV were taken into account (fig. 4). The greatest effects of in utero cigarette smoke exposure were measured in $\mathrm{G}$, which was higher in CS compared with Air pups at both Prs TGV50 (23,267 $\pm 3,847$ versus $20,405 \pm 2,506 \mathrm{hPa} \cdot \mathrm{L}^{-1} ; \mathrm{p}=0.011$ ) and $\operatorname{Prs} 20 \mathrm{cmH}_{2} \mathrm{O}$ $\left(61,000 \pm 10,253\right.$ versus $\left.52,525 \pm 7,052 \mathrm{hPa} \cdot \mathrm{L}^{-1} ; \mathrm{p}=0.018\right)$. H was significantly influenced by in utero tobacco smoke exposure at $P$ rs $20 \mathrm{cmH}_{2} \mathrm{O} \quad\left(466,193 \pm 66,536\right.$ versus $416,928 \pm 63,147 \mathrm{hPa} \cdot \mathrm{L}^{-1}$; $\mathrm{p}=0.017)$ but not at Prs TGV50 $(\mathrm{p}=0.096)$.

There were no significant effects of in utero cigarette smoke on $\eta$ at either Prs. At Prs TGV50, $\eta$ of CS pups was not different from that of Air pups $(0.307 \pm 0.051$ versus $0.322 \pm 0.034 ; p=0.627)$. Similarly, at $\operatorname{Prs} 20 \mathrm{cmH}_{2} \mathrm{O}, \eta$ of CS pups was not different from that of Air pups $(0.131 \pm 0.014$ versus $0.128 \pm 0.013 ; \mathrm{p}=0.451)$.

\section{Histology}

Histology was measured on a randomly selected sub-sample of eight pups from each treatment. There were no differences between CS and Air pups for any histological measurement. $V \mathrm{p}$ was not significantly different between Air and CS pups $\left(140.4 \pm 37.0\right.$ versus $\left.121.8 \pm 15.02 \mathrm{~mm}^{3} ; \mathrm{p}=0.386\right)$. Vs was almost identical between Air and CS pups (52.3 \pm 7.4 versus $\left.52.5 \pm 5.9 \mathrm{~mm}^{3} ; \mathrm{p}=0.953\right)$ and $S$ a was similar between treatments $\left(6,682.4 \pm 609.4\right.$ and $6,091.3 \pm 1,166.1 \mathrm{~mm}^{2}$ for Air pups and CS pups, respectively; $\mathrm{p}=0.404)$. 

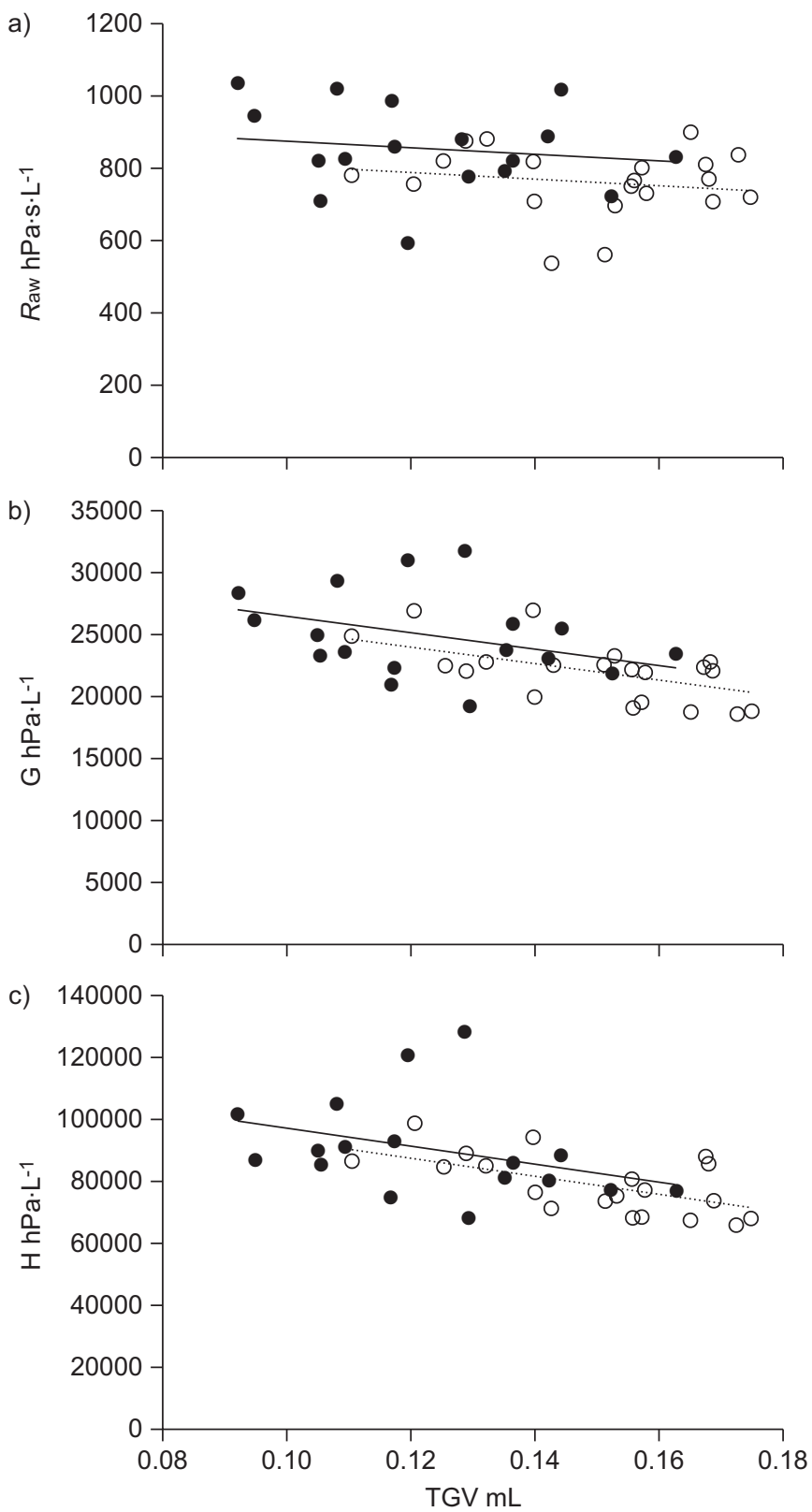

FIGURE 2. Baseline lung mechanics. a) Airway resistance (Raw), b) tissue damping $(\mathrm{G})$ and $\mathrm{c}$ ) tissue elastance $(\mathrm{H})$ for 2-week-old BALB/c pups exposed to mainstream cigarette smoke in utero $(\bullet$ and $-; \mathrm{n}=17)$ and controls $(\bigcirc$ and $\cdots \cdots$; $n=20$ ). Each circle represents an individual pup. TGV: thoracic gas volume.

\section{DISCUSSION}

Pups born from mothers exposed to mainstream cigarette smoke during pregnancy were smaller and had lower lung volumes than control pups, at 2 weeks of age. This impaired development resulted in differences in lung mechanics, particularly when the lungs were inflated. This has important implications in that previous studies have not investigated the potential impacts of in utero cigarette smoke exposure on lung mechanics at high transrespiratory pressures. Differences in airway and parenchymal mechanics with the lungs at rest were explained by difference in lung size, as expressed by lung volume.

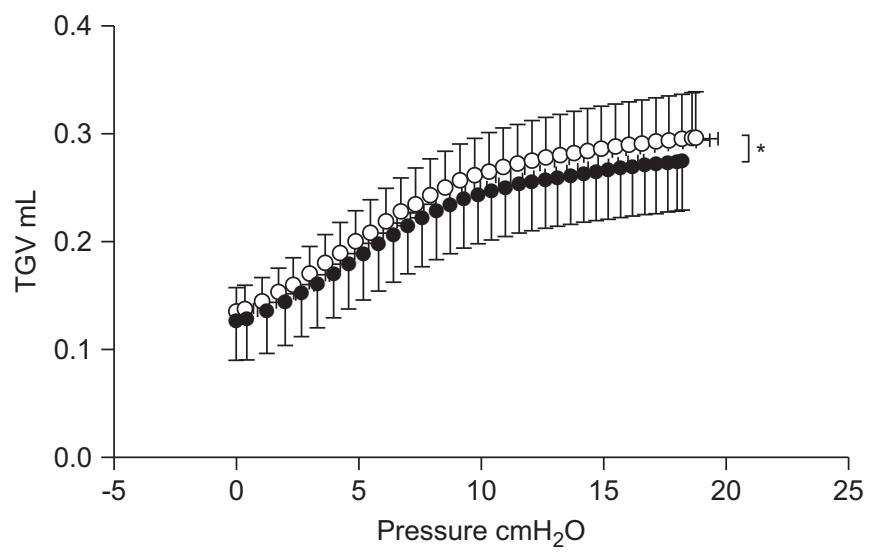

FIGURE 3. Mean pressure-volume curves for inflation-deflation manoeuvres for 2-week-old pups exposed to cigarette smoke in utero (CS pups; $\mathbf{0} ; \mathrm{n}=17$ ) and control pups (Air pups; $\mathrm{O} ; \mathrm{n}=20$ ), starting at $0 \mathrm{cmH}_{2} \mathrm{O}$ transrespiratory pressure up to $20 \mathrm{cmH}_{2} \mathrm{O}$. The maximum thoracic gas volume (TGV) reached for CS pups was significantly less than that reached for Air pups. Data are presented as group mean \pm SD. *: $p<0.05$.

The effects of maternal smoking on intrauterine growth are well documented [2]. It has been known for some time [25] that maternal smoking adversely affects birth weight and length [8], and more recently this effect has been confirmed to be directly dose related [26]. In mouse pups, we found that in utero exposure to cigarette smoke resulted in pups that were almost $1 \mathrm{~g}(\sim 12 \%$ total body weight) lighter than Air pups at 2 weeks of age. Importantly, this was not a function of litter size, nor was it due to preterm delivery, as there were no differences in litter size or gestational period between CS and Air dams. This agrees with the findings of human studies that suggest that the lower weights of babies born to smoking mothers are due to intrauterine growth impairment rather than premature delivery $[8,27,28]$. Babies born to smoking mothers have been estimated to be $5 \%(\sim 150-340 \mathrm{~g})$ lighter per pack of cigarettes smoked per day by the mother [28, 29], and birth weight is significantly lower in babies born to mothers who self-report smoking as little as one cigarette per day [30]. Maternal smoking can alter fetal growth in a number of ways, including transient reductions in maternal uterine blood flow and fetal hypoxia [31,32]. Discussion of these is beyond the scope of this investigation; however, it is also known that impaired intrauterine growth has a lasting effect on subsequent growth and development in children [33] and, as shown in the present study, in utero exposure to cigarette smoke in mice results in lower body weight and TGV at 2 weeks of age.

There is also a relationship between urine cotinine levels (a stable metabolite of nicotine) and birth weight, with increasing urine cotinine being associated with reduced birth weight [30]. Urine cotinine levels similar to those measured in our study (i.e. $\sim 5,800 \mathrm{ng} \cdot \mathrm{mL}^{-1}$ ) resulted in a reduction in birth weight of $\sim 10-12 \%$, which is almost identical to the reduction we measured [30]. Furthermore, it has been shown that levels of cotinine in human urine are $\sim 5,200 \mathrm{ng} \cdot \mathrm{mL}^{-1}$ in adults who smoke 20-60 cigarettes day $^{-1}$ [34], suggesting that our exposure protocol is equivalent to a similar exposure. 

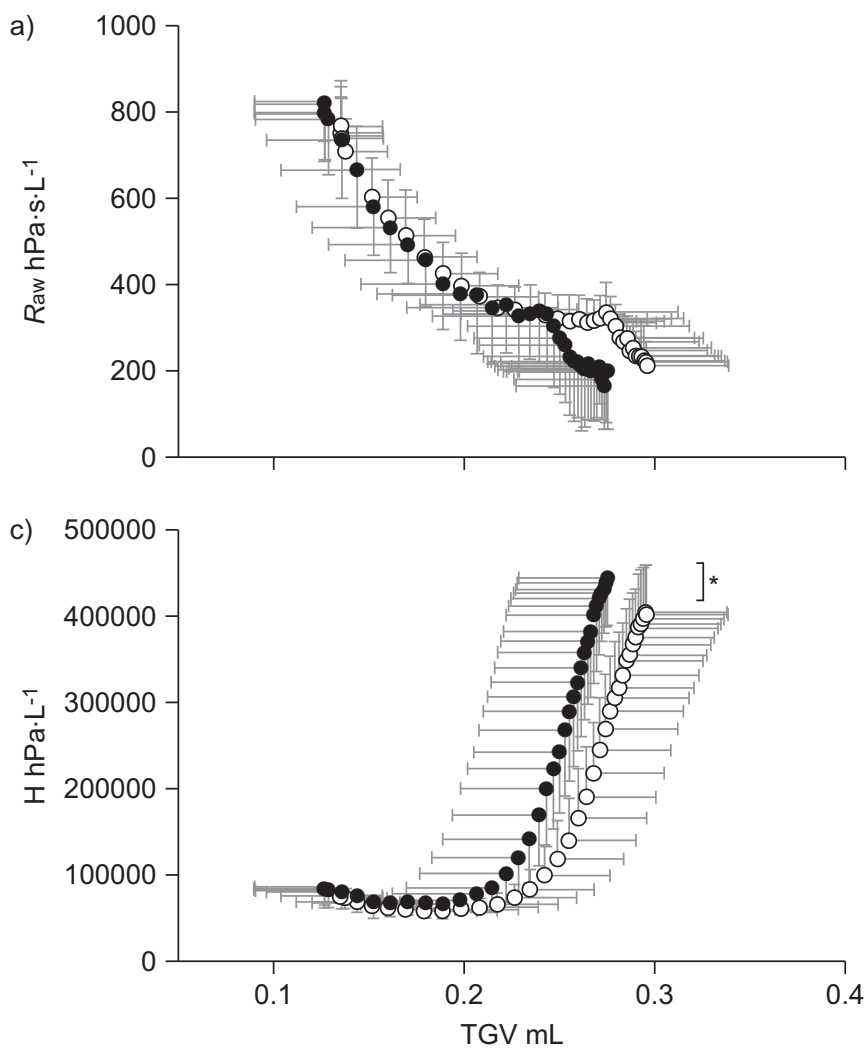

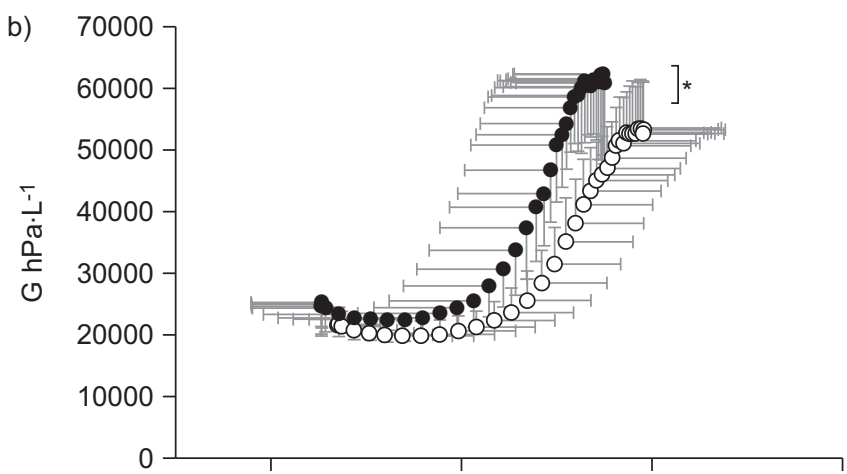

d)

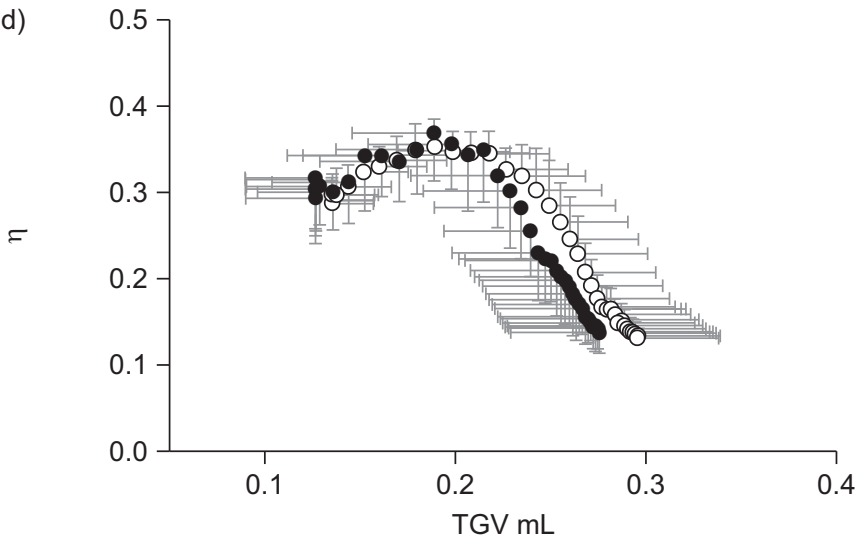

FIGURE 4. Influence of in utero mainstream cigarette smoke exposure on a) airway resistance (Raw), b) tissue damping (G), c) tissue elastance (H) and d) hysteresivity $(\eta)$ of 2-week-old pups during forced inflation from transrespiratory pressure of $0-20 \mathrm{cmH}_{2} \mathrm{O}$. TGV: thoracic gas volume. $\bullet$ : pups exposed to cigarette smoke in utero $(n=17) ; 0$ : control pups $(n=20)$. Data are presented as mean \pm SD. *: $p<0.05$.

Most human studies that investigate the effects of in utero tobacco smoke exposure on lung function at birth, or in early life, account for birth weight in their analyses [8, 12, 35-37]. Generally, these studies find effects of in utero tobacco smoke exposure on lung function shortly after birth, even when differences in birth weight are taken into account. Such studies are forced to try to correct for a plethora of confounders other than birth weight, including gestational age, parental atopy, passive or active smoking and smoking habits (i.e. number of cigarettes per day), all of which can influence the lung function of newborns. Using a mouse model of in utero cigarette smoke exposure allows us to eliminate the effects of these potential confounders.

In our study, CS pups showed impaired lung mechanics with the lungs at rest at the elastic equilibrium volume (greater Raw, G, H and $\eta$ ) compared with Air pups; however, the impairments were attributable to size differences. The smaller overall size, and hence smaller lungs, of CS pups will inherently "cause" apparent impairment in lung function as measured by our techniques. When differences in size are accounted for, CS pups appear to have "normal" lung function; however, having significantly smaller lungs is, in itself, enough to have significant impact on later lung health [38]. Furthermore, our histological measures showed that lung structure was not altered by in utero cigarette smoke exposure, although one might expect the lower TGV of CS pups to be associated with changes in lung structure. These findings strongly suggest that the smaller lung size of CS pups is the primary factor affecting their lung function.
An important finding of our study is the significant influence of in utero cigarette smoke exposure on the volume dependency of lung mechanics, whereby measures of tissue mechanics ( $\mathrm{G}$ and $\mathrm{H}$ ) were significantly higher in CS pups compared with Air pups when the lungs were inflated to a Prs of $20 \mathrm{cmH}_{2} \mathrm{O}$. This impairment was apparent even when differences in TGV were taken into account. This characteristic has been largely overlooked in the literature to date, and may have important implications on how the potential effects of in utero tobacco smoke exposures are assessed in both animals and humans. For example, a higher G in CS pups indicates that they have greater resistance in the peripheral airways and reduced lung compliance compared with Air pups. In addition, a higher $G$ could reflect a greater proportion of closed peripheral lung units [39] or an increase in parallel airway heterogeneity [40,41]. Closed lung units and increased airway heterogeneity could significantly affect overall lung health as these features reflect smaller airways in general, which can result in an increased risk of respiratory infections, wheeze and other respiratory disease [38]. Our estimates of $\mathrm{G}, \mathrm{H}$ and $\eta$ include the mechanical contribution of the chest wall in addition to the lung tissue [42]. In adult mice, the chest wall contributes $\sim 20 \%$ to $G$ but negligibly to $H$. This contribution is likely to be considerably less in the 2-week-old mice in our study where the chest wall is softer; however, the potential contribution should not be ignored.

In conclusion, we measured significant differences in the lung mechanics of 2-week-old BALB/c pups born to mothers exposed to cigarette smoke during pregnancy, compared with 
controls. The greatest impacts stem from the smaller size and smaller TGV of CS pups. These changes may partially explain the increased susceptibility of infants born to mothers who smoke to early respiratory disease and chronic respiratory disease later in life. As such, additional studies investigating whether the measured deficits in size and TGV of mouse pups born to mothers exposed to cigarette smoke during pregnancy are maintained throughout life would be useful. Our findings are supported by epidemiological studies, which show significant impacts of cigarette smoke exposure on intrauterine and postnatal growth in humans [43]. Smaller lungs, and hence smaller airways, in early life also increase the risk of respiratory viral infections, altered lung function, wheeze and other respiratory disorders [35, 44]. Furthermore, impaired lung development in utero has been linked to chronic obstructive pulmonary disease in later life [45]. These findings indicate that insults to the developing fetus can have significant repercussions on respiratory health in later life, regardless of whether the in utero insults directly affect the developing lungs.

\section{SUPPORT STATEMENT}

This research was supported by an Asthma Foundation of Western Australia New Investigator Grant and by the National Health and Medical Research Council of Australia.

\section{STATEMENT OF INTEREST}

None declared.

\section{REFERENCES}

1 Cunningham J, Dockery DW, Speizer FE. Maternal smoking during pregnancy as a predictor of lung function in children. Am J Epidemiol 1994; 139: 1139-1152.

2 DiFranza JR, Aligne CA, Weitzman M. Prenatal and postnatal environmental tobacco smoke exposure and children's health. Pediatrics 2004; 113: Suppl. 4, 1007-1015.

3 Gilliland FD, Berhane K, McConnell R, et al. Maternal smoking during pregnancy, environmental tobacco smoke exposure and childhood lung function. Thorax 2000; 55: 271-276.

4 Gilliland FD, Li YF, Peters JM. Effects of maternal smoking during pregnancy and environmental tobacco smoke on asthma and wheezing in children. Am J Respir Crit Care Med 2001; 163: 429-436.

5 Gilliland FD, Berhane K, Li YF, et al. Effects of early onset asthma and in utero exposure to maternal smoking on childhood lung function. Am J Respir Crit Care Med 2003; 167: 917-924.

6 Lannero E, Wickman M, Pershagen G, et al. Maternal smoking during pregnancy increases the risk of recurrent wheezing during the first years of life (BAMSE). Respir Res 2006; 7: 3 .

7 Li YF, Gilliland FD, Berhane K, et al. Effects of in utero and environmental tobacco smoke exposure on lung function in boys and girls with and without asthma. Am J Respir Crit Care Med 2000; 162: 2097-2104.

8 Lodrup Carlsen KC, Jaakkola JJ, Nafstad P, et al. In utero exposure to cigarette smoking influences lung function at birth. Eur Respir J 1997; 10: 1774-1779.

9 Singh SP, Barrett EG, Kalra R, et al. Prenatal cigarette smoke decreases lung cAMP and increases airway hyperresponsiveness. Am J Respir Crit Care Med 2003; 168: 342-347.

10 Zlotkowska R, Zejda JE. Fetal and postnatal exposure to tobacco smoke and respiratory health in children. Eur J Epidemiol 2005; 20: 719-727.

11 Martinez FD, Cline M, Burrows B. Increased incidence of asthma in children of smoking mothers. Pediatrics 1992; 89: 21-26.
12 Stick SM, Burton PR, Gurrin L, et al. Effects of maternal smoking during pregnancy and a family history of asthma on respiratory function in newborn infants. Lancet 1996; 348: 1060-1064.

13 Seymour BWP, Friebertshauser KE, Peake JL, et al. Gender differences in the allergic response of mice neonatally exposed to environmental tobacco smoke. Dev Immunol 2002; 9: 47-54.

14 Barrett EG, Wilder JA, March TH, et al. Cigarette smoke-induced airway hyperresponsiveness is not dependent on elevated immunoglobulin and eosinophilic inflammation in a mouse model of allergic airway disease. Am J Respir Crit Care Med 2002; 165: 1410-1418.

15 Bowles KS, Horohov DW, Paulsen DB, et al. Exposure of adult mice to environmental tobacco smoke fails to enhance the immune response to inhaled antigen. Inhal Toxicol 2005; 17: 43-51.

16 Joad JP, Ji CM, Kott KS, et al. In utero and postnatal effects of sidestream cigarette smoke exposure on lung function, hyperresponsiveness, and neuroendocrine cells in rats. Toxicol Appl Pharmacol 1995; 132: 63-71.

17 Joad JP, Pinkerton KE, Bric JM. Effects of sidestream smoke exposure and age on pulmonary function and airway reactivity in developing rats. Pediatr Pulmonol 1993; 16: 281-288.

18 Janosi TZ, Adamicza A, Zosky GR, et al. Plethysmographic estimation of thoracic gas volume in apneic mice. J Appl Physiol 2006; 101: 454-459.

19 Sly PD, Collins RA, Thamrin C, et al. Volume dependence of airway and tissue impedances in mice. J Appl Physiol 2003; 94: 1460-1466.

20 Fredberg JJ, Stamenovic D. On the imperfect elasticity of lung tissue. J Appl Physiol 1989; 67: 2408-2419.

21 Petak F, Hantos Z, Adamicza A, et al. Methacholine-induced bronchoconstriction in rats: effects of intravenous vs. aerosol delivery. J Appl Physiol 1997; 82: 1479-1487.

22 Hantos Z, Daroczy B, Suki B, et al. Input impedance and peripheral inhomogeneity of dog lungs. J Appl Physiol 1992; 72: 168-178.

23 Hsia CCW, Hyde DM, Ochs M, et al. An official research policy statement of the American Thoracic Society/European Respiratory Society: standards for quantitative assessment of lung structure. Am J Respir Crit Care Med 2010; 181: 394-418.

24 Nyengaard JR, Gundersen HJG. Sampling for stereology in lungs. Eur Respir Rev 2006; 15: 107-114.

25 Simpson WJ. A preliminary report on cigarette smoking and the incidence of prematurity. Am J Obstet Gynecol 1957; 73: 807-815.

26 MacArthur C, Knox EG. Smoking in pregnancy: effects of stopping at different stages. Br J Obstet Gynaecol 1988; 95: 551-555.

27 Kramer MS. Intrauterine growth and gestational duration determinants. Pediatrics 1987; 80: 502-511.

28 Kramer MS, Olivier M, McLean FH, et al. Determinants of fetal growth and body proportionality. Pediatrics 1990; 86: 18-26.

29 Meyer MB, Comstock GW. Maternal cigarette smoking and perinatal mortality. Am J Epidemiol 1972; 96: 1-10.

30 England LJ, Kendrick JS, Gargiullo PM, et al. Measures of maternal tobacco exposure and infant birth weight at term. Am J Epidemiol 2001; 153: 954-960.

31 Bush PG, Mayhew TM, Abramovich DR, et al. Maternal cigarette smoking and oxygen diffusion across the placenta. Placenta 2000; 21: 824-833.

32 Morrow RJ, Ritchie JW, Bull SB. Maternal cigarette smoking: the effects on umbilical and uterine blood flow velocity. Am J Obstet Gynecol 1988; 159: 1069-1071.

33 Biber A, Scherer G, Hoepfner I, et al. Determination of nicotine and cotinine in human serum and urine: an interlaboratory study. Toxicol Lett 1987; 35: 45-52.

34 Barros FC, Huttly SR, Victora CG, et al. Comparison of the causes and consequences of prematurity and intrauterine growth retardation: a longitudinal study in southern Brazil. Pediatrics 1992; 90: 238-244.

35 Hanrahan JP, Tager IB, Segal MR, et al. The effect of maternal smoking during pregnancy on early infant lung function. Am Rev Respir Dis 1992; 145: 1129-1135. 
36 Tager IB, Ngo L, Hanrahan JP. Maternal smoking during pregnancy. Effects on lung function during the first 18 months of life. Am J Respir Crit Care Med 1995; 152: 977-983.

37 Young S, Le Souef PN, Geelhoed GC, et al. The influence of a family history of asthma and parental smoking on airway responsiveness in early infancy. N Engl J Med 1991; 324: 1168-1173.

38 Barker DJ, Godfrey KM, Fall C, et al. Relation of birth weight and childhood respiratory infection to adult lung function and death from chronic obstructive airways disease. BMJ 1991; 303: 671-675.

39 Lutchen KR, Gillis H. Relationship between heterogeneous changes in airway morphometry and lung resistance and elastance. J Appl Physiol 1997; 83: 1192-1201.

40 Lutchen KR, Greenstein JL, Suki B. How inhomogeneities and airway walls affect frequency dependence and separation of airway and tissue properties. J Appl Physiol 1996; 80: 1696-1707.
41 Lutchen KR, Hantos Z, Petak F, et al. Airway inhomogeneities contribute to apparent lung tissue mechanics during constriction. J Appl Physiol 1996; 80: 1841-1849.

42 Bozanich EM, Collins RA, Thamrin C, et al. Developmental changes in airway and tissue mechanics in mice. J Appl Physiol 2005; 99: 108-113.

43 Hofhuis W, de Jongste JC, Merkus PJFM. Adverse health effects of prenatal and postnatal tobacco smoke exposure on children. Arch Dis Child 2003; 88: 1086-1090.

44 Dezateux C, Stocks J, Dundas I, et al. Impaired airway function and wheezing in infancy: the influence of maternal smoking and a genetic predisposition to asthma. Am J Respir Crit Care Med 1999; 159: 403-410.

45 Coultas DB. Health effects of passive smoking. 8. Passive smoking and risk of adult asthma and COPD: an update. Thorax 1998; 53: 381-387. 